\title{
Phenotypic, Molecular, and Pathological Characterization of Colletotrichum acutatum Associated with Andean Lupine and Tamarillo in the Ecuadorian Andes
}

César E. Falconí, Agropecuarian Science Faculty, Life Science Department, Army Polytechnic School, Sangolqui, Ecuador; and Richard G. F. Visser and Adriaan W. van Heusden, Wageningen UR Plant Breeding, Wageningen, The Netherlands

\begin{abstract}
Falconí, C. E., Visser, R. G. F., and van Heusden, A. W. 2013. Phenotypic, molecular, and pathological characterization of Colletotrichum acutatum associated with Andean lupine and tamarillo in the Ecuadorian Andes. Plant Dis. 97:819-827.

Anthracnose is a serious problem of both Andean lupine and tamarillo in Ecuador. Morphological features, internal transcribed spacer (ITS) sequences, and host specificity were used to characterize Colletotrichum isolates from lupine and tamarillo. Based on phenotypic and molecular characterization, the causal agent of anthracnose on both hosts was Colletotrichum acutatum. All isolates were identified in a $C$. acutatum-specific polymerase chain reaction assay. Colony diameter, conidia shape, and insensitivity to benomyl also placed isolates from both hosts in the $C$. acutatum group. However, a detailed analysis of the ITS sequences placed the lupine and tamarillo isolates from the Ecuadorian Andean zone in two clades, with both lupine and tamarillo

isolates in each clade. C. acutatum isolates from Andean lupine were distinct from other $C$. acutatum isolates on lupine around the world. In cross-infection studies, the diameter of lesions produced by isolates from each host was compared on the main stem of two tamarillo and three lupine cultivars. Some isolates produced larger lesions on the host from which they were isolated but others showed similar aggressiveness on their alternate host. Isolates from both hosts were biotrophic on lupine stems, producing little necrosis and abundant sporulation whereas, on tamarillo stems, they produced dark lesions with few conidia. The collection of $C$. acutatum isolates from lupine and tamarillo provides interesting material for the study quantitative host adaptation.
\end{abstract}

Andean lupine (Lupinus mutabilis Sweet) is a native legume that has much to offer in support of nutritional self-sufficiency for the Andean people due to its high levels of protein ( $>40 \%$ in dry grain) $(8,18)$, fat $(20 \%)$, iron, zinc $(8)$ carbohydrates, minerals, and fibers (20). Lupine, known locally as chocho, plays a role in many production systems in the Ecuadorian highland and is cultivated in intercropping, monoculture, and rotation systems (30).

Tamarillo (Solanum betaceum Cav.), another native Ecuadorian plant, grows as a small tree or shrub, bearing edible egg-shaped fruit with a thin skin and soft flesh when ripe (33). Traditionally, lupine has been cultivated in colder areas $(5,23)$ and tamarillo in somewhat warmer areas $(33,34)$. Due to increased demand for lupine, this is changing (43), and host adaptation of anthracnose will have important epidemiological consequences in areas where two or more potential hosts grow in close proximity.

Worldwide, there are several species of Colletotrichum that can cause anthracnose on legumes, perennial crops, and vegetables $(12,13,40)$. In lupine, anthracnose causes a typical twisting of petioles and stems or pods, with dark sunken lesions, in the center of which orange conidial masses are produced (Fig. 1A-D). On tamarillo branches, anthracnose symptoms include dark, depressed lesions varying in size and form (Fig. 1E) and black lesions on fruit accompanied by erumpent pink conidia masses in the lesions. Ultimately, the fruit is deformed and rots completely (Fig. 1F). In Ecuador, yield losses due to anthracnose can reach up to $100 \%$ in lupine (27) and 60\% in tamarillo $(3,34)$.

Species identification in Colletotrichum has relied mainly on morphology and host range $(11,36)$. The growth of isolates in media amended with benomyl (1) is also a discriminating characteris-

Corresponding author: C. E. Falconí, E-mail: cefalconi@espe.edu.ec

* The $\boldsymbol{e}$-Xtra logo stands for "electronic extra" and indicates that Figures 1 and 2 appear in color online.

Accepted for publication 7 January 2013.

http://dx.doi.org/10.1094/PDIS-02-12-0175-RE

(C) 2013 The American Phytopathological Society tic. Still, these characteristics are often unreliable to properly determine the species of an isolate (4,36). Colletotrichum acutatum can be pathogenic and nonpathogenic and can grow on a number of different hosts (38). Multiple Colletotrichum spp. have been implicated as the causal agents of anthracnose in lupine and tamarillo. The sequence of the internal transcribed spacer (ITS) region (ITS1 to ITS2) of ribosomal DNA (rDNA) shows that anthracnose on lupine (41) and tamarillo (2) is caused by $C$. acutatum and not $C$. gloeosporioides, which was originally thought to be the causal agent $(3,7,19,33,34,51)$. C. lupini has also been designated as the causal agent of lupine anthracnose $(28,45)$. The objectives of this study were to (i) determine the causal agent of lupine and tamarillo anthracnose in Ecuador, (ii) analyze lupine and tamarillo Colletotrichum isolates from Ecuador based on their ITS sequence, and (iii) assess the pathogenic variability and cross-infection potential. To the best of our knowledge, this is the first study of anthracnose in Ecuador in which phenotypic and molecular approaches are combined to characterize the population structure of this important pathogen. These findings will help in the development of appropriate disease management and efficient breeding strategies.

\section{Materials and Methods}

Fungal isolates. In 2007, 2010, and 2011, symptomatic lupine stems and tamarillo fruit were collected from several production areas in Ecuador. In total, 23 Colletotrichum isolates were considered for this study, 18 from lupine and 5 from tamarillo (Table 1) Isolates from lupine were obtained from main stems with dark sunken lesions, in the center of which orange conidial masses were produced (Fig. 1C). Isolates from tamarillo were collected from depressed black lesions on fruit accompanied by erumpent pink conidia in the lesions (Fig. 1F). Not all isolates were used in all the analyses and further details are provided in the appropriate sections. Stock cultures of single-conidia isolates were stored at $-10^{\circ} \mathrm{C}$ in suspensions consisting of $1 \mathrm{~g}$ of autoclaved peat $+10 \%$ autoclaved sucrose in 2.0-ml cryotubes (Genaxxon). Isolates were propagated by growing small amounts of frozen conidial suspension from cryotubes to petri dishes containing potato dextrose agar (PDA; Difco Laboratories).

Morphological studies. Colony characteristics (transparency, presence of conidial masses, presence and color of concentric 
bands, pigmentation, and growth pattern) were determined for each isolate. Isolates retrieved from cryopreservation were grown on PDA for 10 days and a conidial suspension in water of $10^{6}$ conidia/ml was prepared. The suspension $(15 \mu \mathrm{l})$ was pipetted in the center of a petri dish (PDA amended with Cloramphenicol [Chloromycetin Parke Davis Co.] at $500 \mathrm{mg} / \mathrm{liter}$ ) and three replications for each isolate were incubated at $17 \pm 2^{\circ} \mathrm{C}$ in daylight. The colony characteristics listed above were determined after 10 days of incubation.

The growth rate of all isolates on PDA at $15,20,25$, and $30^{\circ} \mathrm{C}$ in the dark was measured. Each isolate had three replications which were evaluated daily over 5 days, and the maximum final growth was recorded. The experiments were conducted twice and the means over both replications calculated. The colony radius with three replicates, four measurements per replicate, was analyzed using analysis of variance, least significant differences, and coefficient of variation determined with the Statistic Software Infostat (www.infostat.com.ar).

Twenty-five conidia for each isolate were assessed for morphometric measurements. Conidia size was measured with an ocular micrometric scale (Nikon) at $\times 100$ magnification and conidia shape determined from isolates incubated for 5 days on PDA at 17 $\pm 2^{\circ} \mathrm{C}$ in daylight.

Benomyl sensitivity of the isolates was assessed by comparing colony radius on PDA and on PDA amended with benomyl (Benlate 50WP; DuPont) at $2 \mathrm{mg} / \mathrm{liter}$. Six isolates from lupine and three isolates from tamarillo were tested twice in duplicate. Colony radius mean values of both experiments were compared with isolates grown on PDA and the reference isolate of $C$. gloeosporioides IMI 356878 (GenBank accession AJ536229.1). A colony radius reduction of greater than $30 \%$ was considered positive.
DNA preparation. Lupine and tamarillo isolates were grown on PDA at $25^{\circ} \mathrm{C}$ for 6 days. Mycelium was collected from the plates with a scalpel, frozen in liquid nitrogen, and ground in a mortar to a fine powder. DNA extractions were performed using approximately $100 \mathrm{mg}$ of powdered mycelium with an EZNA Fungal DNA kit (Omega Bio-tek) according to the manufacturer's instructions. DNA samples were diluted to a final concentration of 50 to $100 \mathrm{ng} / \mu \mathrm{l}$.

Taxon-specific polymerase chain reaction amplification. Polymerase chain reaction (PCR) primers for taxon-specific amplification included the ITS4 (49) primer coupled with specific primers for $C$. acutatum (CaInt2) (GGGGAAGCCTCTCGCGG) $(4,37)$ and $C$. gloeosporioides (CgInt) (GGCCTCCCGCCT CCGGGCGG) (4). PCR reactions were performed for 30 cycles $\left(30 \mathrm{~s}\right.$ at $95^{\circ} \mathrm{C}, 30 \mathrm{~s}$ at $60^{\circ} \mathrm{C}$, and $1.5 \mathrm{~min}$ at $72^{\circ} \mathrm{C}$ ). Amplification products were separated in $1.5 \%$ agarose gels in Tris-acetateEDTA buffer (32) at $80 \mathrm{~V}$ for $2 \mathrm{~h}$. A 100-bp ladder (Invitrogen) was used as molecular standard.

PCR amplification and sequencing of ITS1, 5.8S, and ITS4 regions of the rDNA genes. Universal PCR primers ITS1 and ITS4 were used to amplify the ITS regions between the small and large nuclear rDNA, including the ITS2 and the 5.8S rDNA (49). PCR reactions were carried out on a Techne DNA Thermal Cycler TC-512 in $100 \mu \mathrm{l}$, containing 50 to $100 \mathrm{ng}$ of DNA, 50 $\mathrm{mM} \mathrm{KCl}, 10 \mathrm{mM}$ Tris-HCl (pH 7.5), $80 \mu \mathrm{M}$ (each) dNTP, $1 \mu \mathrm{M}$ each primer, $2 \mathrm{mM} \mathrm{MgCl}$, and $1 \mathrm{U}$ of DNA polymerase (Invitrogen). The temperature regime of the 40 cycles was $30 \mathrm{~s}$ at $95^{\circ} \mathrm{C}, 1 \mathrm{~min}$ at $44^{\circ} \mathrm{C}$, and $1 \mathrm{~min}$ at $72^{\circ} \mathrm{C}$. PCR products were purified with the UltraClean PCR Clean-up DNA Purification kit (MoBio) and sequenced using the TaqDyeDeoxy terminator cycle sequencing kit (Applied Biosystems), according to the manufac-
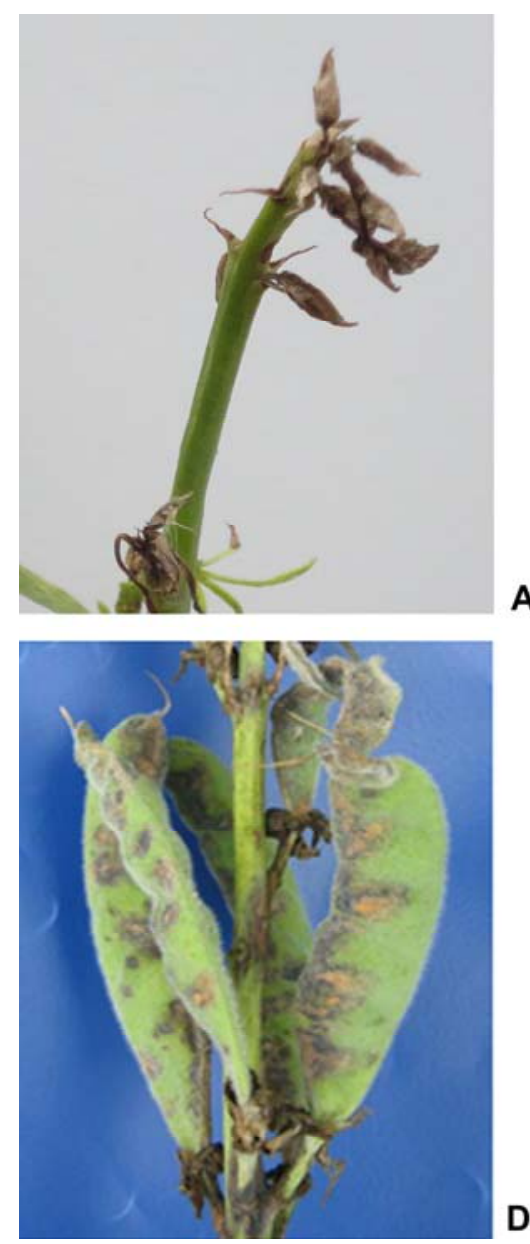
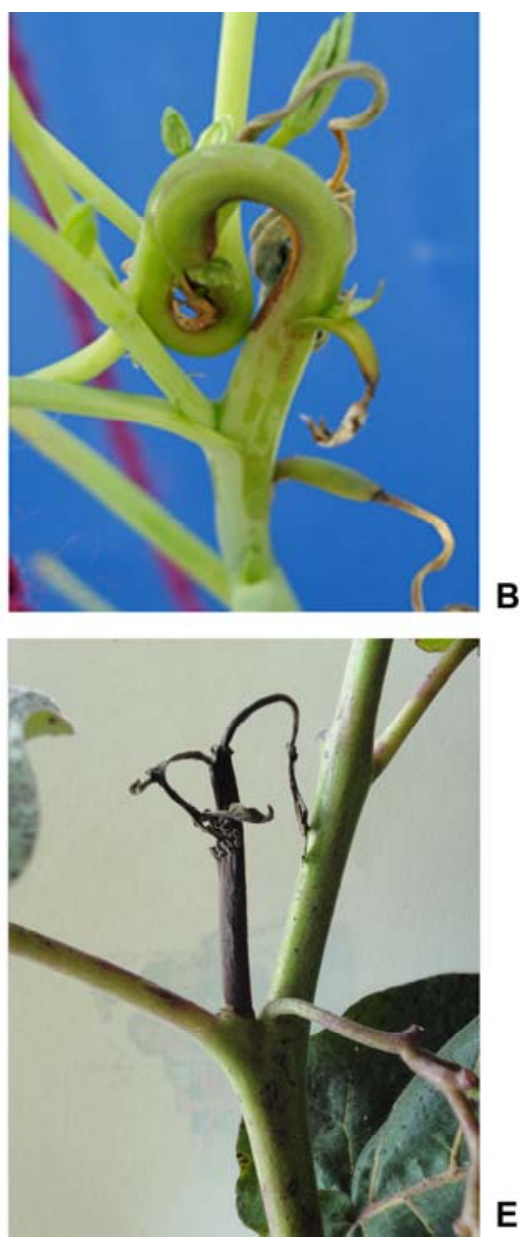
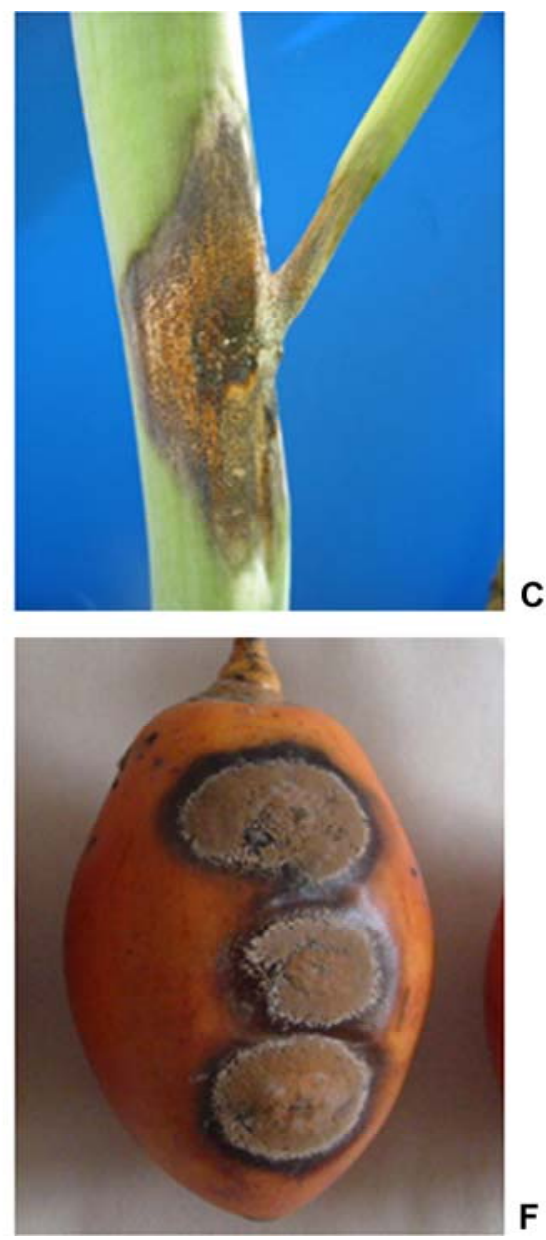

Fig. 1. Anthracnose symptoms caused by natural infection of Colletotrichum acutatum on lupine (Lupinus mutabilis) A, on leaves; $\mathbf{B}$, on the apical main stems; C, on the main stems; and D, on the pods. E, Anthracnose symptoms on tamarillo (Solanum betaceum) main stem and F, symptoms on tamarillo fruit. 
turer's instructions, in an Applied Biosystems automatic DNA sequencer model 373A.

Phylogenetic analysis. ITS sequences obtained in this study were compared with ITS sequences of other lupine isolates $(C$. acutatum, C. lupini var. lupini, and C. lupini var. setosum), tamarillo (C. acutatum), and C. acutatum isolates from other hosts from all over the world. Initial comparisons of cognate sequences available in GenBank (www.ncbi.nlm.nih.gov/genbank) were made using the BLAST algorithm. Phylograms based on ITS1 sequence comparisons were constructed using the neighbor-joining (NJ) (31) and maximum parsimony (MP) methods in MEGA 4 (Molecular Evolutionary Genetic Analysis Software version 4 for Windows). $\mathrm{NJ}$ analysis was conducted using the MP model for estimating evolutionary distance $\left(d_{i j}\right)$ between DNA frequencies. The MP tree was obtained using the close-neighbor-interchange algorithm. Model parameters were empirically determined from the sequences. Bootstrap analysis with 1,000 repetitions was performed to test the significance of the nodes and the robustness of the tree (17). In addition to the sequences generated in this study and other sequences from lupine and tamarillo around the world, interspecific multiple alignments included other ITS1 sequences of $C$. fragariae, C. gloeosporioides, and C. falcatum obtained from GenBank. Neurospora crassa was used as an outgroup (6). The ITS1 sequences of the isolates in this study are deposited in GenBank (www.ncbi.nlm.nih.gov/genbank).

Aggressiveness on alternate host. Differential aggressiveness for five isolates from lupine and five from tamarillo was tested in a cross-inoculation experiment. This study used 1.5-month-old lupine seedlings and 2.0-month-old tamarillo seedlings. Each isolate was evaluated on the host from which it was isolated (host of origin) and on the alternate host. Three susceptible cultivars of lupine ('ECU-2658', 'ECU-7112-1', and 'ECU-722-4') and two susceptible cultivars of tamarillo ('Gigante comun' and 'Comun') were used. Inoculum was prepared by flooding PDA plates on which the isolate had grown for 10 days at $25^{\circ} \mathrm{C}$ with $4 \mathrm{ml}$ of $0.01 \%$ Tween- 80 solution and rubbing with a sterile glass rod. The conidial suspensions were diluted to a final concentration of $10^{6}$ conidia/ml of saline solution $(0.05 \% \mathrm{NaCl}+0.01 \%$ Tween- 80$)$. In preliminary tests, spraying the pathogen reproduced the symptoms in only some individuals of both hosts. A wounding method was chosen to avoid escapes. A hypodermic syringe $(0.2 \mathrm{~mm}$ in diameter and $0.3 \mathrm{~mm}$ in depth) was used to injure lupine or tamarillo plants at the apical main stem. A $20-\mu l$ droplet of conidia $\left(10^{6}\right.$ conidia/ml) was used for inoculation. The inoculated lupine and tamarillo plants, along with appropriate controls, which were treated with sterile distilled water, were incubated in a tunnel greenhouse with $100 \%$ relative humidity at $20 \pm 2{ }^{\circ} \mathrm{C}$. Lesion size was measured with a ruler parallel to the main stems 20 days after inoculation. Symptoms were compared on both hosts. At the end of the study, the pathogen was reisolated from lupine or tamarillo stems, in order to verify that it was the inoculated pathogen. The significance of the interaction between isolates and hosts was tested with analysis of variance. The experiment was conducted twice and the mean of both assays was reported. Each plant-pathogen combination was represented by three plants of lupine for each pot or one plant of tamarillo per pot and replicated three times. One wound was made in each lupine plant and two wounds per tamarillo plant. The mean lesion length of three lupine plants or two lesions on tamarillo in each pot was the basic unit for analysis. The sources of variance analyzed were the (inoculated) host (lupine or tamarillo), the original host of the isolate (lupine or tamarillo), and the combination original host-inoculated host.

\section{Results}

Culture and morphological characteristics. The colony morphology of all isolates (upper and lower surface) was consistent with published descriptions of $C$. acutatum species $(21,39,44)$. All isolates presented either a white-pink or a gray-pink pigmentation on the reverse. The growth of the isolates was regular and progressive on PDA and, after 10 days at $17 \pm 2{ }^{\circ} \mathrm{C}$ in daylight, the petri dish surface was one-third to two-thirds covered in case of the lupine isolates and almost fully covered by the tamarillo isolates. Three of eight of the lupine and tamarillo isolates formed white to pale aerial mycelium which was cottony and often dense near the center, and the other five developed olive-gray mycelium (Fig. 2A versus $\mathrm{B}, \mathrm{C}$, and $\mathrm{D}$ ). Concentric white and dark-pink circles were seen on the mycelium of lupine isolates. White-pink colonies are generally related to $C$. acutatum and gray-dark ones to $C$. gloeosporioides (39). The tamarillo isolates showed different colony morphology, either with white mycelium slowly turning to a salmon color and without concentric circles (Fig. 2E) or with white mycelium slowly turning gray and producing circles around the center of the culture (Fig. 2F). In general, the colony color of isolates from both lupine and tamarillo changed in time from white to

Table 1. Colletotrichum spp. isolates collected in Ecuadorian provinces

\begin{tabular}{|c|c|c|c|c|}
\hline Original code & Host species & Affected tissue & Location, province & Collection date \\
\hline Lup1 & Lupine & Stem & Juan Montalvo, Cotopaxi & 2007 \\
\hline Lup2 & Lupine & Stem & Pangigua grande, Cotopaxi & 2007 \\
\hline Lup3 & Lupine & Stem & Pusuchusi, Cotopaxi & 2007 \\
\hline Lup4 & Lupine & Stem & Picualo Alto, Cotopaxi & 2007 \\
\hline Lup5 & Lupine & Stem & San Juan, Cotopaxi & 2007 \\
\hline Tam6 & Tamarillo & Fruit & San Pablo, Imbabura & 2007 \\
\hline Tam7 & Tamarillo & Fruit & Ibarra, Imbabura & 2007 \\
\hline Lup8 & Lupine & Stem & San Marcos, Cotopaxi & 2007 \\
\hline Lup10 & Lupine & Stem & El Tejar, Cotopaxi & 2007 \\
\hline Lup11 & Lupine & Stem & Chinchil, Cotopaxi & 2007 \\
\hline Lup12 & Lupine & Stem & Chinchil Robayo, Cotopaxi & 2007 \\
\hline Lup14 & Lupine & Stem & Canchicera, Cotopaxi & 2007 \\
\hline Lup16 & Lupine & Stem & San Francisco, Cotopaxi & 2007 \\
\hline Lup18 & Lupine & Stem & Pujili, Cotopaxi & 2007 \\
\hline Tam20 & Tamarillo & Fruit & Guallabamba, Pichincha & 2010 \\
\hline Lup21 & Lupine & Stem & Tixan, Chimborazo & 2010 \\
\hline Lup24 & Lupine & Stem & Guamote, Chimborazo & 2010 \\
\hline Lup28 & Lupine & Stem & Palmira, Chimborazo & 2010 \\
\hline Lup30 & Lupine & Stem & Lican, Chimborazo & 2010 \\
\hline Lup31 & Lupine & Stem & Guazazo, Chimborazo & 2010 \\
\hline Lup32 & Lupine & Stem & San Andres, Chimborazo & 2010 \\
\hline Tam33 & Tamarillo & Fruit & Atuntaqui, Imbabura & 2011 \\
\hline Tam34 & Tamarillo & Fruit & Cotacachi, Imbabura & 2011 \\
\hline IMI $356878^{a}$ & Olive & Fruit & Montsia, Tarragona, Spain & 2003 \\
\hline
\end{tabular}

a Reference isolate IMI 356878 (AJ536229.1) (Colletotrichum gloeosporioides) from olive (Olea europaea subsp. europaea) was kindly provided by Dr. Pedro Martinez-Culebras (IATA, Universidad de Valencia, Spain). 
dark but conidia were consistently pink-salmon. C. acutatum isolates from lupine release a pink-salmon pigment that differs from a pink-yellow pigment of tamarillo isolates on PDA.

Radial growth of the fungal mycelium showed a high variability between isolates at $15,20,25$, and $30^{\circ} \mathrm{C}$ in the dark (Table 2). However, growth rate was more homogeneous between isolates at $25^{\circ} \mathrm{C}$. Because of the smaller variation coefficient and the least significant differences at $25^{\circ} \mathrm{C}$, the isolates could be divided into various groups. We separated them into three groups: a slow-growing group (Lup4), the fast-growing group (Tam6, Tam7, and $C$. gloeosporioides reference isolate), and an intermediate-growing group (Lup1, Lup14, Lup16, Lup18, Lup28, and Tam20). At 30 ${ }^{\circ} \mathrm{C}$, the growth rate of the fungi reduced. Radial growth of tamarillo isolates was faster than that of the lupine isolates at $25^{\circ} \mathrm{C}$. In each group, a higher average of radial growth at four temperatures of incubation was obtained for Tam7 and Lup18. The lower growth at 20 than at either 15 or $25^{\circ} \mathrm{C}$ of some isolates may be an intrinsic character

The shape of the conidia varied between lupine isolates at $17 \pm$ $2{ }^{\circ} \mathrm{C}$. Conidia of isolates Lup1 and Lup 28 were ovoid, with one round and one acute end (Fig. 2A), but conidia of the other lupine isolates were mostly cylindrical, with round ends, resembling $C$. gloeosporioides (Fig. 2B-D). Conidia of tamarillo isolate Tam6 had acute ends typical for C. acutatum (Fig. 2E), whereas Tam7 and Tam 20 had one round and one acute end (Fig. 2F). Because isolates Lup14, Lup16, and Lup18 showed cylindrical, roundedend conidia and gray-olive colonies, they were placed in a separate group (Table 3 ). Length and width ranges of the conidia of the lupine and tamarillo isolates overlapped (Table 3).

Benomyl test. The benomyl sensitivity assay indicated differences between $C$. acutatum and $C$. gloeosporioides. Lupine and tamarillo isolates showed radial mycelium growth of 30 to $50 \%$ on benomyl-amended PDA in comparison with the controls (Table 2). The reference isolate of C. gloeosporioides IMI 356878 (GenBank accession AJ536229.1) did not grow in PDA amended with benomyl.

Species-specific primer analyses. DNA from 10 Colletotrichum isolates collected from lupine and tamarillo was isolated A 490-bp DNA fragment was amplified with the C. acutatumspecific primers CaInt2 and ITS4 in all lupine and tamarillo isolates. The $C$. gloeosporioides-specific 450-bp DNA fragment was only amplified in the reference isolate $C$. gloeosporioides IMI 356878 (GenBank accession AJ536229.1; Table 2).

Sequencing of rDNA region. Colletotrichum isolates from lupine (Lup1, Lup12, Lup14, Lup16, Lup18, Lup24, and Lup28) and tamarillo (Tam6, Tam7, and Tam20) were used for sequence analysis of the ITS region. The results were compared with published Colletotrichum ITS sequences from lupine (28,41), tamarillo (2), strawberry (25), olive $(40,42)$, and $C$. fioriniae com et stat nov. and C. simmondsii sp. nov. reclassified by Shivas and Tan (35), for-
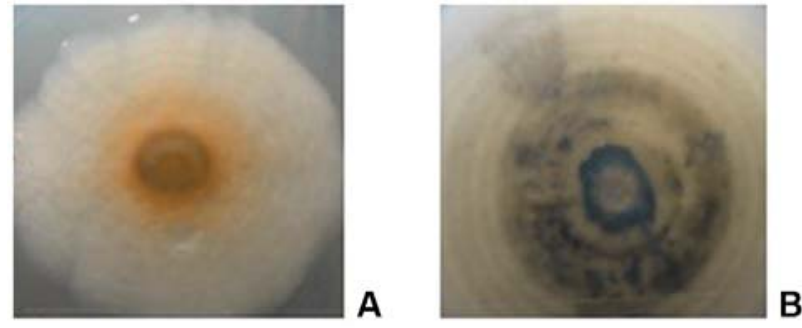

B
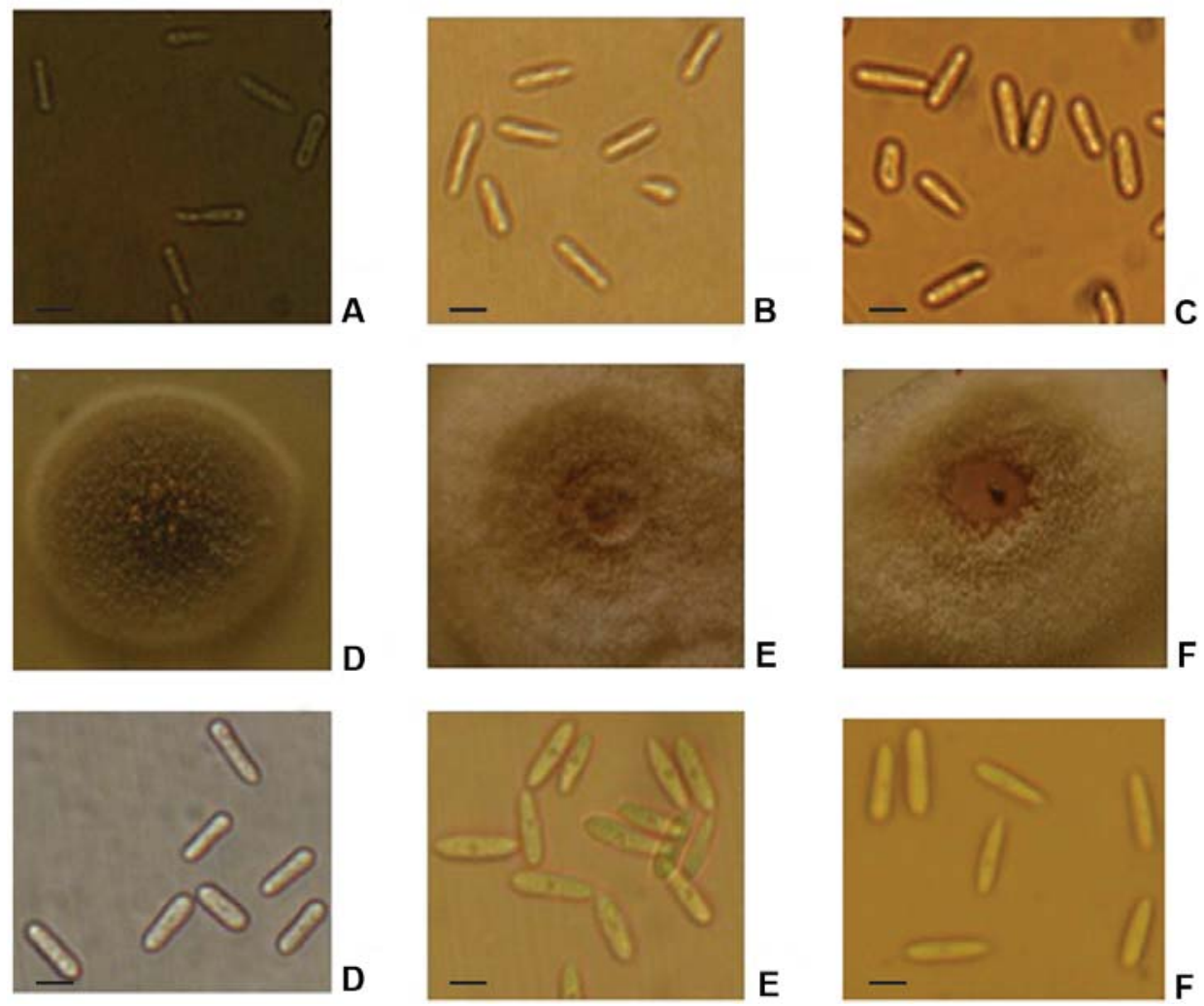

Fig. 2. Colony and conidial morphological variability of Colletotrichum acutatum isolates from lupine (Lupinus mutabilis) and tamarillo (Solanum betaceum) grown for 10 days at $17 \pm 2{ }^{\circ} \mathrm{C}$ at day light on potato dextrose agar plates. A, Inverse colony surface and conidia shape of isolate Lup1; $\mathbf{B}$, inverse colony surface and conidia shape of isolate Lup14; C, upper colony surface and conidia shape of isolate Lup16; D, upper colony surface and conidia shape of isolate Lup18; $\mathbf{E}$, upper colony surface and conidia shape of isolate Tam6; and F, upper colony surface and conidia shape of isolate Tam20 (each division line $=10.0 \mu \mathrm{m}$ ). 
merly C. acutatum in the EMBL database. Sequences of additional representative isolates of the species $C$. gloeosporioides, C. fragariae, and C. falcatum were also included (25; Table 4). The phylogenetic analyses of 38 taxa of Colletotrichum were completed by applying the NJ and MP models (Fig. 3). Phylograms were generated to confirm interspecific separation of C. acutatum from lupine and tamarillo with C. gloeosporioides, C. fragariae, and C. falcatum. Removing highly variable positions from the sequence analysis did not affect tree topology. Sequence analysis confirmed that all lupine and tamarillo isolates were $C$. acutatum.

In the phylograms, most Ecuadorian $C$. acutatum lupine isolates were in one subgroup together with Tam6. Other tamarillo isolates (Tam7 and Tam20, two from Colombia) were in subgroup III together with Lup28. Other subgroups in the phylogenetic tree consisted of isolates from around the world. For instance, subgroup I consisted of one C. acutatum from lupine (41), one from olive (42), and four C. lupini from lupine (28). One C. acutatum isolate from lupine (41), one from primula (28), and two $C$. fioriniae com. et stat. nov. of mango and avocado (35) formed subgroup II. Subgroups I, II, and III and the lupine subgroup from Ecuador formed group I. One isolate from strawberry (25) and one from tamarillo, cited as Cyphomandra betacea (35), were placed within the separate group II. Two isolates from olive $(40,42)$, one Colletotrichum sp. from lupine (41), and two Colletotrichum simmonsii from tomato and chili (35) formed a separate clade (group III) (Fig. 3).
In the final dataset, 62 of 460 positions were informative: sequence comparisons gave a homology level of 98.9 to $100 \%$ in group I and of 99.6 to $100 \%$ in its subgroups. Tree topology was similar for NJ and MP trees with respect to placement of taxa.

Aggressiveness on alternate host. Five $C$. acutatum isolates from lupine and five from tamarillo were tested for their aggressiveness on three lupine and two tamarillo genotypes. The interaction between the inoculated host and the source of the pathogen (original host) was highly significant $(P<0.0001)$ for lesion length (Table 5). With tamarillo as host, $22.00 \mathrm{~mm}$ was the maximum lesion length, and this was $24.00 \mathrm{~mm}$ with lupine as host (Table 6). Some isolates, such as Tam20, Lup18, and Lup28, caused larger lesions on their original host as on the alternative host. However, there were also cases in which isolates were similarly aggressive. Isolate Lup4 was the most pathogenic on all lupine and tamarillo cultivars.

Symptom expression on lupine was similar for the two populations of $C$. acutatum studied here. Isolates from lupine were highly biotrophic in lupine, producing little or no necrosis on lupine stems after 20 days following infection. Abundant salmon-colored sporulation and intense production of mycelium were also observed 7 days after inoculation. In contrast, isolates from tamarillo sporulated less abundantly on tamarillo and induced dark pigmentation in the lesions, with sporulation appearing 15 days after inoculation. In the host cross test, isolates of tamarillo were also biotrophic on lupine stems, producing little necrosis with sporulation after 7 days, but isolates of lupine produced dark pigmentations with almost no sporulation in tamarillo stems.

Table 2. Cumulative mycelial radial growth of Colletotrichum isolates from Lupinus mutabilis and Solanum betaceum incubated at $25^{\circ} \mathrm{C}$ for 5 days on potato dextrose agar (PDA) in the dark, relative sensitivity in PDA amended with benomyl, and polymerase chain reaction amplification products using primers CaInt2/internal transcribed spacer (ITS4) and CgInt/ITS4

\begin{tabular}{|c|c|c|c|c|c|c|c|}
\hline \multirow[b]{2}{*}{ Isolate $^{\mathrm{c}}$} & \multicolumn{4}{|c|}{ Radial growth for 5 days $(\mathrm{mm})^{a}$} & \multirow[b]{2}{*}{ Benomyl sensitivity $^{\mathrm{d}}$} & \multicolumn{2}{|c|}{ Primer reaction $^{\mathbf{b}}$} \\
\hline & $15^{\circ} \mathrm{C}$ & $2^{\circ} \mathrm{C}$ & $25^{\circ} \mathrm{C}$ & $30^{\circ} \mathrm{C}$ & & CaInt2 & CgInt \\
\hline Lup1 & 40.1 & 41.7 & 48.6 & 28.3 & + & + & - \\
\hline Lup4 & 45.4 & 45.4 & 44.0 & 23.5 & + & + & - \\
\hline Lup14 & 41.2 & 36.3 & 54.4 & 24.7 & + & + & - \\
\hline Lup16 & 39.4 & 37.0 & 59.3 & 30.0 & + & + & - \\
\hline Lup18 & 44.0 & 44.0 & 60.6 & 36.2 & + & + & - \\
\hline Lup28 & 44.8 & 44.3 & 49.9 & 19.2 & + & + & - \\
\hline Tam6 & 47.7 & 35.6 & 64.8 & 20.8 & + & + & - \\
\hline Tam7 & 51.7 & 48.5 & 64.6 & 23.9 & + & + & - \\
\hline Tam20 & 45.4 & 43.5 & 60.0 & 20.8 & + & + & - \\
\hline IMI 356878 & 24.5 & 40.2 & 64.5 & 28.2 & - & - & + \\
\hline LSD & 1.02 & 0.46 & 0.13 & 0.34 & $\ldots$ & $\ldots$ & $\ldots$ \\
\hline $\mathrm{CV}$ & 2.07 & 0.97 & 0.20 & 1.18 & $\ldots$ & $\ldots$ & $\ldots$ \\
\hline
\end{tabular}

${ }^{a}$ Radial growth of isolates on PDA at selected temperatures in the dark was measured using colonies initiated from $15-\mu \mathrm{ldroplet}$ of $1 \times 10^{6} \mathrm{conidia}^{\mathrm{ml}}{ }^{-1}$. Each isolate had three replications, four measurements per replicate, and final maximum growth up to 5 days.

${ }^{\mathrm{b}}$ Taxon-specific primers CaInt2 (Colletotrichum acutatum), and CgInt (C. gloeosporioides) were coupled with primer ITS4 for species identification; a positive (+) or negative $(-)$ reaction with fungal DNA of each isolate is designated.

${ }^{c}$ Reference isolate IMI 356878 (AJ536229.1) (C. gloeosporioides) from olive (Olea europaea subsp. europaea) was included. LSD = least significant difference and $\mathrm{CV}=$ coefficient of variation.

${ }^{d}$ Benomyl sensitivity of the isolates was assessed by comparing colony radius on PDA and PDA amended with benomyl (Benlate 50WP, DuPont) at 2 $\mathrm{mg}$ liter ${ }^{-1}$; growth (+) or non-growth (-) mycelial reaction is indicated.

Table 3. Conidia and colony morphology of representative isolates of Colletotrichum spp. from lupine and tamarillo species in Ecuador grown for 10 days at $17 \pm 2^{\circ} \mathrm{C}$ in day light on potato dextrose agar (PDA) plates

\begin{tabular}{|c|c|c|c|}
\hline Isolate & Host & Conidia morphology and size & Colony morphology on PDA \\
\hline $\begin{array}{l}\text { Lup1, } \\
\text { Lup28 }\end{array}$ & Lupine & $\begin{array}{l}\text { Ovoid, one round and one acute end, } \\
10.0 \text { to } 13.0 \text { by } 4.5 \text { to } 5.0 \mu \mathrm{m}\end{array}$ & $\begin{array}{l}\text { Transparent, cottony, and low-density colonies with abundant pink-orange conidia } \\
\text { masses in the center, transparent concentric bands, pink-salmon pigment covers } \\
\text { one-third of the colony surface, no setae or "hair-like structures" present on PDA }\end{array}$ \\
\hline $\begin{array}{l}\text { Lup14, } \\
\text { Lup16, } \\
\text { Lup18 }\end{array}$ & Lupine & $\begin{array}{l}\text { Cylindrical, rounded-end conidia or } \\
\text { one round and one acute end, } \\
12.5 \text { to } 18.0 \text { by } 5.0 \text { to } 5.5 \mu \mathrm{m}\end{array}$ & $\begin{array}{l}\text { Gray-olive, felty and medium dense colonies with pink conidia masses, dark concentric } \\
\text { bands, sclerotia present, pink-salmon pigment covers two-thirds to three-thirds of the } \\
\text { colony surface, setae presence or not }\end{array}$ \\
\hline Tam6 & Tamarillo & $\begin{array}{l}\text { Elliptic, pointed at both ends, } \\
12.5 \text { to } 18.0 \text { by } 2.5 \text { to } 4.5 \mu \mathrm{m}\end{array}$ & $\begin{array}{l}\text { White mycelium, turning salmon with age due to proliferation of conidia masses; no } \\
\text { sclerotia present; setae present, no concentric bands presence, yellow-salmon pigment } \\
\text { cover two-thirds of the colony surface }\end{array}$ \\
\hline $\begin{array}{l}\text { Tam7, } \\
\text { Tam20 }\end{array}$ & Tamarillo & $\begin{array}{l}\text { Elliptic and pointed at one end, } \\
14.0 \text { to } 18.5 \text { by } 4.5 \text { to } 6.0 \mu \mathrm{m}\end{array}$ & $\begin{array}{l}\text { White mycelium turning gray and powdery with pink conidia masses, salmon in color, } \\
\text { produced outward in circles from the center of the culture, sclerotia present, setae } \\
\text { present, concentric circles form the center of the colony, yellow-salmon pigment } \\
\text { covers two-thirds to three-thirds of the colony surface }\end{array}$ \\
\hline
\end{tabular}




\section{Discussion}

In this study, we demonstrate that the causal agent of lupine and tamarillo anthracnose in Ecuador is $C$. acutatum. Other species of Colletotrichum have been implicated as causes of anthracnose in these hosts, including $C$. lupini. Based on morphological features such as colony color and conidia shape, Nirenberg et al. (28) separated $C$. lupini var. lupini from $C$. lupini var. setosum. We disagree with the separation of this species into two separate varieties because, in our study, morphological traits of isolates overlapped and it was very difficult to separate them.

Morphological evaluation of isolates from both hosts demonstrated the variability possible in this species. In general, the colony color of isolates both lupine and tamarillo changed in time from white to dark but conidia were consistently pink-salmon. Pink-salmon-colored conidia is a characteristic of $C$. acutatum in formal descriptions $(21,39,44)$. Growth rate and pigment can be considered as parameters to differentiate isolates of lupine and tamarillo. C. acutatum lupine isolates grow more slowly than tamarillo isolates and produce a pink-salmon pigment (tamarillo isolates produce a pink-yellow pigment). These morphological characteristics correlated with molecular analysis and lupine and tamarillo isolates clustered in two different groups based on ITS sequences (Fig. 3). In our study, we noticed that some C. acutatum isolates from lupine and tamarillo grew faster at 15 and 25 than at $20^{\circ} \mathrm{C}$.
This may be an adaption to lower temperatures at night and higher temperatures during the day, with only a short period of intermediate temperatures. Nirenberg et al. (28) and Thomas et al. (45) demonstrated that maximum growth of Colletotrichum isolates from lupine was at $25^{\circ} \mathrm{C}$; mycelial growth was reduced and conidia not swollen when isolates were grown at $30^{\circ} \mathrm{C}$.

Lupine Colletotrichum spp. produced conidia that were ovoid, with either one rounded and one pointed end (Fig. 2A) or with a cylindrical shape (Fig. 2B-D). Cylindrical conidia have often been associated with $C$. gloeosporioides (39) and this might be the reason that others have determined $C$. gloeosporioides to be the causal agent of anthracnose in lupine and not $C$. acutatum, although molecular analysis with random amplified polymorphic DNA isolates indicated differently $(7,51)$. In our study, we found cylindrical, pointed at one end or ovoid conidia of $C$. acutatum (Fig. 2A-D). Conidia of tamarillo isolates had either acute ends typical for $C$. acutatum or one round and one acute end (Fig. 2E and F). Morphology of conidia can be affected by differences in artificial conditions but direct identification of isolates coming from the plant is also difficult because conidia morphology varies during the infection process. The use of morphological features to distinguish Colletotrichum taxa in general is tricky due to the lack of standardized protocols and international rules and, therefore, taxonomic relationships within the genus are unlikely to be resolved only by the use of traditional morphological characters (39).

Table 4. Internal transcribed spacer 1 and 2 sequences of Colletotrichum isolates used in this study

\begin{tabular}{|c|c|c|c|c|}
\hline Isolate code & EMBL accession & Determination by the authors as & Host & Country \\
\hline BBA 70343 PD 93/1373 & AJ301915 & Colletotrichum acutatum $^{\mathrm{a}}$ & Primula & The Netherlands \\
\hline BBA 70344 PD 93/1436 & AJ301916 & C. lupini var. setosum ${ }^{\mathrm{a}}$ & Lupinus sp. & The Netherlands \\
\hline BBA 700073 & AJ301927 & C. lupini var. setosum ${ }^{\mathrm{a}}$ & Lupinus polyphyllus hybrid & Germany \\
\hline BBA 63879 & AJ301930.1 & C. lupini var. lupini ${ }^{\mathrm{a}}$ & L. mutabilis & Bolivia \\
\hline \multirow[t]{9}{*}{ BBA 70884} & AJ301948 & C. lupini var. lupini $i^{\mathrm{a}}$ & L. albus & Ukraine \\
\hline & AJ300559 & Colletotrichum sp. ${ }^{\mathrm{b}}$ & L. angustifolius & Portugal \\
\hline & AJ300563 & Colletotrichum $\mathrm{sp} .^{\mathrm{b}}$ & L. mutabilis & Portugal \\
\hline & AJ311391 & C. acutatum $^{\mathrm{b}}$ & L. albus & Canada \\
\hline & AJ300558 & C. acutatum $^{\mathrm{b}}$ & L. albus & Portugal \\
\hline & AJ749674 & C. acutatum $^{\mathrm{c}}$ & Olea europaea subsp. europaea & Portugal \\
\hline & AJ749679 & C. acutatum $^{\mathrm{d}}$ & O. europaea subsp. europaea & Portugal \\
\hline & AM991131 & Glomerella acutata $^{\mathrm{e}}$ & O. europaea subsp. europaea & Portugal \\
\hline & AM991137 & G. acutata $^{\mathrm{e}}$ & O. europaea subsp. europaea & Portugal \\
\hline Lup1 & JN543059f & C. acutatum & L. mutabilis & Ecuador \\
\hline Tam6 & JN543069f & C. acutatum & Solanum betaceum & Ecuador \\
\hline Tam7 & JN543070 f & C. acutatum & S. betaceum & Ecuador \\
\hline Lup12 & JN543060 f & C. acutatum & L. mutabilis & Ecuador \\
\hline Lup14 & JN543061 ${ }^{\mathrm{f}}$ & C. acutatum & L. mutabilis & Ecuador \\
\hline Lup16 & JN543062 & C. acutatum & L. mutabilis & Ecuador \\
\hline Lup18 & JN543063 f & C. acutatum & L. mutabilis & Ecuador \\
\hline $\operatorname{Tam} 20$ & JN543071 $1^{\mathrm{f}}$ & C. acutatum & S. betaceum & Ecuador \\
\hline Lup21 & JN543064 & C. acutatum & L. mutabilis & Ecuador \\
\hline Lup24 & JN543065 & C. acutatum & L. mutabilis & Ecuador \\
\hline Lup28 & JN543066 f & C. acutatum & L. mutabilis & Ecuador \\
\hline Lup30 & JN543067 & C. acutatum & L. mutabilis & Ecuador \\
\hline \multirow[t]{3}{*}{ Lup31 } & JN543068f & C. acutatum & L. mutabilis & Ecuador \\
\hline & AF521205 & C. acutatum $^{\mathrm{g}}$ & S. betaceum & Colombia \\
\hline & AF521210 & C. acutatum $^{\mathrm{g}}$ & S. betaceum & Colombia \\
\hline 345034 & AJ536207 & C. acutatum $^{\mathrm{h}}$ & Fragaria $\times$ ananassa & Australia \\
\hline 356878 & AJ536229 & C. gloeosporioides ${ }^{\mathrm{h}}$ & Fragaria $\times$ ananassa & Italy \\
\hline 345047 & AJ536223 & C. fragariae & Fragaria $\times$ ananassa & United States \\
\hline 347765 & AJ536231 & C. falcatum ${ }^{\mathrm{h}}$ & Fragaria $\times$ ananassa & Bangladesh \\
\hline 20127 & GU183320 & C. fioriniae ${ }^{\mathrm{i}}$ & Persea americana & Australia \\
\hline 28761 & GU183333 & C. fioriniae ${ }^{\mathrm{i}}$ & Mangifera indica & Australia \\
\hline 24191 & GU183322 & C. simmondsii ${ }^{\mathrm{i}}$ & Actinia chinensis & Australia \\
\hline 28420 & GU183327 & C. simmondsii $i^{\mathrm{i}}$ & Cyphomandra betacea & Australia \\
\hline 52657 & GU183352 & Colletotrichum simmondsii ${ }^{\mathrm{i}}$ & Lycopersicon esculentum & Australia \\
\hline
\end{tabular}

a Isolate sequenced by Nirenberg et al. (28).

${ }^{\mathrm{b}}$ Isolate sequenced by Talhinhas et al. (41).

${ }^{\mathrm{c}}$ Isolate sequenced by Talhinhas et al. (2005; EMBL direct submission).

d Isolate sequenced by Talhinhas et al. (42).

${ }^{\mathrm{e}}$ Isolate sequenced by Talhinhas et al. (40).

${ }^{\mathrm{f}}$ Isolates sequenced by the authors (2011; EMBL accession number).

${ }^{\mathrm{g}}$ Isolate sequenced by Afanador-Kafuri et al. (2).

${ }^{\mathrm{h}}$ Isolate sequenced by Martinez-Culebras et al. (25).

${ }^{\mathrm{i}}$ Isolate sequenced by Shivas and Tan (35). 
Primers specific for $C$. acutatum and $C$. gloeosporioides have been used previously to show that $C$. acutatum is the causal agent of lupine anthracnose in Portugal (41), tamarillo anthracnose in Colombia (2), and almond anthracnose in California (9), and that both $C$. acutatum and $C$. gloeosporioides are responsible for anthracnose of olive in Portugal (42). In this study, the use of specific primers supported the identification of $C$. acutatum as the causal agent of lupine and tamarillo anthracnose in the Ecuadorian Andean zone.

C. acutatum can be distinguished based on the ability to grow on PDA with benomyl at $2 \mathrm{mg} / \mathrm{liters}$ (Table 2) but differential sensitivity of mixed Colletotrichum populations to fungicides such as benomyl can pose problems in disease control (15). In tamarillo, we can speculate that the outbreak of anthracnose in tamarillo is from endemic resistant populations of $C$. acutatum.

Phylogenetic analysis of the ITS sequences divided the C. acutatum lupine and tamarillo populations from Ecuador into two sub- groups and most (one exception) lupine isolates formed one new subgroup (Fig. 3). Earlier studies showed that in strawberry, the pathogen population within a geographical location was very homogeneous and nearly clonal (24-26). This was also found for C. acutatum populations on strawberry in a number of locations in the United States (46) and in several locations in Israel (10). In this study, the new subgroup of lupine isolates included one from tamarillo. This isolate was collected in an area where lupine and tamarillo have been cultivated together for about 10 years and it might be a lupine isolate that cross infected a field of tamarillo. Subgroup III grouped tamarillo isolates from Ecuador and Colombia and one lupine isolate (Lup28) (Fig. 3). Based on sequence analysis of the ITS2 region, two subgroups of $C$. acutatum isolates were found on tamarillo (2); in one of these clades, two isolates of lupine known as $C$. lupini var. lupini and C. lupini var. setosum (28) were present. Based on these findings, Afanador-Kafuri et al. (2) suggested that isolates in this clade may not be host specific.

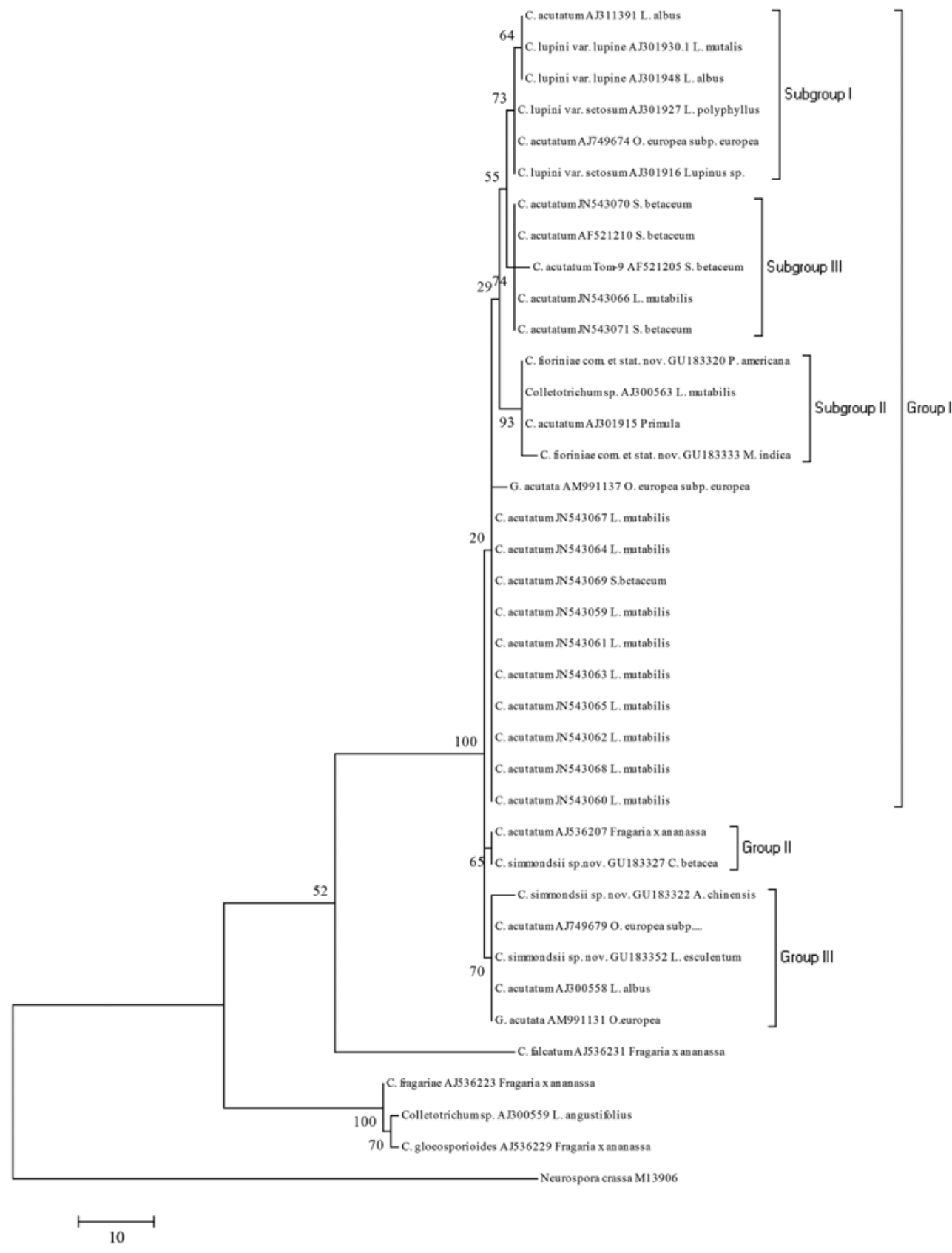

Fig. 3. Phylogram generated from internal transcribed spacer data of Colletotrichum isolates from Lupinus mutabilis, Solanum betaceum, and other hosts around the world using neighbor-joining analysis by using the maximum parsimony model. The optimal tree is shown. Percentage of replicate trees in which associated taxa clustered together in the bootstrap (1,000 replicates) is shown next to the branch nodes. All positions containing gaps and missing data were eliminated from the dataset. Database accession number is provided for reference sequences of Table 1. 
Table 5. Analysis of variance of the lesion length using a general linear model ${ }^{\mathrm{a}}$

\begin{tabular}{lcrrr}
\hline Variable & & & \multicolumn{2}{c}{ Lesion length } \\
\cline { 3 - 5 } Inoculated host (I) & df & MS & F value \\
Host of origin (H) & 1 & 2.67 & 0.05 & 0.65 \\
I $\times$ H & 1 & 339.79 & 0.8196 & 22.40 \\
\hline
\end{tabular}

${ }^{a}$ Components of variance are the inoculated host (lupine or tamarillo) in this assay, host of origin (lupine or tamarillo) from which isolates were collected, and the combination inoculated host per original host of the isolates; $\mathrm{df}=$ degree of freedom, MS = mean square.

Table 6. Diameter (mm) of lesions on three lupine cultivars and two tamarillo cultivars caused by isolates of Colletotrichum acutatum

\begin{tabular}{|c|c|c|c|c|c|c|c|}
\hline \multirow[b]{2}{*}{ Source isolate } & \multicolumn{4}{|c|}{ Lupine cultivars } & \multicolumn{3}{|c|}{ Tamarillo cultivars } \\
\hline & ECU-2658 & ECU-7112-2 & ECU- 722-4 & Mean & Gigante comun & Comun & Mean \\
\hline \multicolumn{8}{|l|}{ Tamarillo } \\
\hline Tam6 & 13.33 & 18.66 & 16.00 & 16.00 & 22.00 & 18.33 & 20.17 \\
\hline Tam7 & 16.00 & 16.00 & 16.00 & 16.00 & 22.00 & 14.66 & 18.33 \\
\hline $\operatorname{Tam} 20$ & 6.00 & 8.00 & 13.33 & 9.11 & 22.00 & 22.00 & 22.00 \\
\hline Tam33 & 16.00 & 5.33 & 21.33 & 14.22 & 22.00 & 14.66 & 18.33 \\
\hline Tam34 & 18.66 & 10.66 & 10.66 & 13.33 & 18.33 & 11.00 & 14.67 \\
\hline Mean & 14.00 & 11.73 & 15.46 & 13.73 & 21.27 & 16.13 & 18.70 \\
\hline \multicolumn{8}{|l|}{ Lupine } \\
\hline Lup1 & 24.00 & 21.33 & 21.33 & 22.22 & 22.00 & 22.00 & 22.00 \\
\hline Lup4 & 24.00 & 24.00 & 24.00 & 24.00 & 22.00 & 22.00 & 22.00 \\
\hline Lup14 & 18.66 & 13.33 & 24.00 & 18.66 & 22.00 & 14.66 & 18.33 \\
\hline Lup18 & 24.00 & 21.33 & 24.00 & 23.11 & 14.66 & 0.00 & 7.33 \\
\hline Lup28 & 21.33 & 24.00 & 24.00 & 23.11 & 18.33 & 3.66 & 11.00 \\
\hline Mean & 22.40 & 20.80 & 23.47 & 22.22 & 19.80 & 12.46 & 16.13 \\
\hline
\end{tabular}

Host range tests clearly showed that lupine and tamarillo are attacked by two separate, host-adapted populations of $C$. acutatum (Table 6). Based on symptoms and lesion size, it is concluded that host adaptation is quantitative rather than qualitative, because isolates were aggressive on their original host but also pathogenic on their alternative host. C. acutatum isolates have also been found on tamarillo, lupine, and other hosts $(2,41)$ in other parts of the world. Whitelaw-Wecket et al. (50) showed there was cross infection of $C$. acutatum, C. fioriniae, and C. simmondsii in different horticultural crops. In our study, lupine isolates were highly biotrophic on lupine but the lupine-adapted isolates caused darkly pigmented lesions on tamarillo stems, which may be classified as a partially necrotrophic reaction. Tamarillo isolates were necrotropic on tamarillo but the lesions that tamarillo-adapted isolates caused in lupine stems were typical of a biotrophic reaction.

Host adaptation appears to be manifested based on lesion size and sporulation in the alternative host (Table 6). The infection strategy adopted by $C$. acutatum depends on the host being colonized and this fungus may also change its infection strategy when colonizing different tissue, hosts, and cultivars (48). We found early and more sporulation of $C$. acutatum in lupine than in tamarillo. Adaptation to a new host is not always associated with reduced fitness in the original host $(22,29,47)$ and, until more components of aggressiveness (infection efficiency and sporulation in the field, among others) are determined, anthracnose integrated management efforts for both lupine and tamarillo should be coordinated.

\section{Acknowledgments}

This research was financially supported by TELFUN project-Wageningen University under the supervision of Wageningen UR Plant Breeding and supported by the Army Polytechnic School (ESPE), Quito-Ecuador. We thank P. V. Martinez-Culebras from IATA, University of Valencia, Spain, for his suggestions and for providing reference isolates; M. Rivera for his help in sampling pathogens; and P. Landazuri and C. Rosas for their help in collecting data.

\section{Literature Cited}

1. Adaskaveg, J. E., and Hartin R. J. 1997. Characterization of Colletotrichum acutatum isolates causing anthracnose of almond and peach in California. Phytopathology 87:979-987.

2. Afanador-Kafuri, L., Minz, D., Maymon, M., and Freeman, S. 2003. Characterization of Colletotrichum isolates from tamarillo, passiflora, and mango in Colombia and identification of a unique species from the genus.
Phytopathology 93:579-587.

3. Albornoz, G. 1992. El Tomate de árbol Cyphomandra betacea Sendt en el Ecuador, Universidad Central, Fundación para el desarrollo agropecuario.

4. Brown, A. E., Sreenivasaprasad, S., and Timmer, L. W. 1996. Molecular characterization of slow-growing orange and key lime anthracnose strains of Colletotrichum from citrus as C. acutatum. Phytopathology 86:523-527.

5. Caicedo, C., and Peralta, E. 2000. Zonificación potencial, sistemas de producción y procesamiento artesanal del chocho (Lupinus mutabilis Sweet) en Ecuador. Bol. Técnico No. 89. Estación Experimental Santa Catalina INIAP.

6. Chambers, C., Dutta, S. K., and Crouch, R. J. 1986. Neurospora crassa ribosomal DNA: sequence of internal transcribed spacer and comparison with $N$. intermedia and $N$. sitophila. Gene 44:159-164.

7. Elmer, W. H., Yang, H. A., and Sweetingham, M. W. 2001. Characterization of Colletotrichum gloeosporoides isolates from ornamental lupines in Connecticut. Plant Dis. 85:216-219.

8. Falconi, C. E. 2012. Lupinus mutabilis in Ecuador with special emphasis on anthracnose resistance. Ph.D. thesis, Plant Breeding Laboratory, Wageningen University, The Netherlands.

9. Förster, H., and Adaskaveg, J. E. 1999. Identification of subpopulations of Colletotrichum acutatum and epidemiology of almond anthracnose in California. Phytopathology 89:1056-1065.

10. Freeman, S., and Katan, T. 1997. Identification of Colletotrichum species responsible for anthracnose and root necrosis of strawberry in Israel. Phytopathology 87:516-521.

11. Freeman, S., Katan, T., and Shabi, E. 1996. Characterization of Colletotrichum gloeosporioides isolates from avocado and almond fruits with molecular and pathogenicity tests. Appl. Environ. Microbiol. 62:1014-1020.

12. Freeman, S., Katan, T., and Shabi, E. 1998. Characterization of Colletotrichum species responsible for Anthracnose diseases of various fruits. Plant Dis. 82(6):596-604.

13. Freeman, S., Minz, D., Jurkevitch, E., Maymon, M., and Shabi, E. 2000. Molecular analyses of Colletotrichum species from almond and other fruits. Phytopathology 90:608-614.

14. Freeman, S., Minz, D., Maymon, M., and Zveibil, A. 2001. Genetic diversity within Colletotrichum acutatum sensu Simmonds. Phytopathology 91:586-592.

15. Freeman, S., Shabi, E., and Katan, T. 2000. Characterization of Colletotrichum acutatum causing anthracnose of anemone (Anemone coronaria L.). Appl. Environ. Microbiol 66:5267-5272.

16. Guerber, J. C., Liu, B., Correll, J. C., and Johnston P R. 2003. Characterization of diversity in Colletotrichum acutatum sensu lato by sequence analysis of two gene introns, mtDNA and intron RFLPs, and mating compatibility. Mycologia 95:872-895.

17. Hills, D. M., and Bull, J. J. 1993. An empirical test of bootstrapping as a method for assessing confidence in phylogenetic analysis. Syst. Biol. 42:182-192.

18. INEN. 2004. Norma Técnica Ecuatoriana INEN 2 390: Grano desamargado de chocho, Requisitos. Instituto Ecuatoriano de Normalización, Quito, Ecuador. 
19. Insuati, M. 2001. Enfermedades foliares. Pages 24-25 in: El Cultivo del Chocho Lupinus mutabilis Sweet Fitonutricion, enfermedades y Plagas en el Ecuador. E. Peralta and E. Caicedo, eds. Bol. Técnico No. 103. INIAP

20. Jacobsen, S., and Mujica, A. 2006. Pages 458-482 in: El tarwi (Lupinus mutabilis Sweet) y sus parientes silvestres. Universidad Mayor de San Andrés, La Paz, Bolivia.

21. Lardner, R., Johnston, P. R., Plummer, K. M., and Pearson, M. N. 1999. Morphological and molecular analysis of Colletotrichum acutatum sensu lato. Mycol. Res. 103:275-285.

22. Lebreton, L., and Andrivon, D. 1998. French isolates of Phytophthora infestans from potato and tomato differ in phenotype and genotype. Eur. J. Plant Pathol. 104:583-594.

23. Llamuca, A. 2006. Plan de Desarrollo de la parroquia Las Pampas, Cantón Sigchos, Provincia de Cotopaxi, SENPLADES.

24. Martínez-Culebras, P. V., Barrio, E., Suarez-Fernandez, M. B., GarcíaLopez, M. D., and Querol, A. 2002. RAPD analysis of Colletotrichum species isolated from strawberry and the design of specific primers for the identification of $C$. fragariae. J. Phytopathol. 150:680-686.

25. Martínez-Culebras, P. V., Querol, A., Suarez-Fernandez, M. B., GarcíaLopez, M. D., and Barrio, E. 2003 Phylogenetic relationships among Colletotrichum pathogens of strawberry and design of PCR primers for their identification. J. Phytopathol. 151:135-143.

26. Muñoz, J. A. G., Suárez, M. B., Grondona, I., Monte, E., Buddie, A. G., Bridge, P. D., and Cannon, P. F. 2000. A physiological and biochemical approach to the systematics of Colletotrichum species pathogenic to Strawberry. Mycologia 92:488-498.

27. Murillo, A., Rivera, M., Peralta, E., Mazon, N., and Vargas, F. 2006. Avances preliminares en el mejoramiento genético del choco (Lupinus mutabilis Sweet) para resistencia a antracnosis. Memorias del XII Congreso Internacional de cultivos andinos, INIAP, Ecuador.

28. Nirenberg, H. I., Feiler, U., and Hagedorn G. 2002. Description of Colletotrichum lupini comb. nov. in modern terms. Mycologia 94:307-320.

29. Oyarzun, P. J., Pozo, A., Ordonez, M. E., Doucett, K., and Forbes, G. A. 1998. Host specificity of Phytophthora infestans on tomato and potato in Ecuador. Phytopathology 88:265-271.

30. Peralta, E., Mazon, N., Murillo, A., Rivera, M., and Monar, C. 2008. Manual Agricola de granos andinos: chocho, quinua, amaranto y ataco. Cultivos, variedades y costos de producción. Manual No. 69. Segunda impresión, E.E.S.C-INIAP.

31. Saitou, N., and Nei, M. 1987. The neighbour-joining method: a new method for reconstruction phylogenetic trees. Mol. Biol. Evol. 4:406-425.

32. Sambrook, J., Fritsch, E. F., and Maniatis, T. 1989. Molecular Cloning: A Laboratory Manual, 2nd ed. Cold Spring Harbor Laboratory, Cold Spring Harbor, NY.

33. Sánchez, A., López, I., Salazar, J., and Fiallos, V. 1996. Manejo integral del cultivo del tomate de árbol. Proyecto FAO/TCP/ECU/2353.

34. Santillán, F. 2001. Manual del cultivo sustentable de tomate de árbol. Universidad de Cuenca, Ecuador.

35. Shivas, R. G., and Tan, Y. P. 2009. A taxonomic re-assessment of Colletotrichum acutatum, introducing C. fioriniae comb. et stat. nov. and C. simmondsii sp. nov. Fungal Divers. 39:111-122.

36. Sreenivasaprasad, S., Mills, P. R., Meehan, B. M., and Brown, A. E. 1996. Phylogeny and systematics of 18 Colletotrichum species based on riboso- mal DNA spacer sequences. Genome 39:499-512.

37. Sreenivasaprasad, S., Sharada, K., Brown, A. E., and Mills, P. R. 1996. PCR-based detection of Colletotrichum acutatum on strawberry. Plant Pathol. 45:650-655.

38. Sreenivasaprasad, S., and Talhinhas, P. 2005. Genotypic and phenotypic diversity in Colletotrichum acutatum, a cosmopolitan pathogen causing anthracnose on a wide range of hosts. Mol. Plant Pathol. 6:361-378.

39. Sutton, B. C. 1992. The genus Glomerella and its anamorph Colletotrichum. Pages 1-26 in: Colletotrichum: Biology, Pathology, and Control. J. A. Bailey and M. J. Jeger, eds. CAB International, Wallingford, UK.

40. Talhinhas, P., Neves-Martins, J., Oliveira, H., and Sreenivasaprasad, S 2009. The distinctive population structure of Colletotrichum species associated with olive anthracnose in the Algarve region of Portugal reflects a hostpathogen diversity hot spot. FEMS Microbiol. Lett. 296:31-38.

41. Talhinhas, P., Sreenivasaprasad, S., Neves-Martin, J., and Oliveira, H. 2002 Genetic and morphological characterization of Colletotrichum acutatum causing anthracnose of lupins. Phytopathology 92:986-996.

42. Talhinhas, P., Sreenivasaprasad, S., Neves-Martins, J., and Oliveira, H. 2005. Molecular and phenotypic analyses reveal the association of diverse Colletotrichum acutatum groups and a low level of $C$. gloeosporioides with olive anthracnose. Appl. Environ. Microbiol. 71:2987-2998.

43. Terán, J. F. 2007. Cotopaxi, una provincia con una miseria no excepcional. En Capítulo V. publicación: Las quimeras y sus caminos. La gobernanza del agua y sus dispositivos para la producción de pobreza rural en los Andes ecuatorianos. FLACSO, Consejo Latinoamericano de Ciencias Sociales.

44. Than, P. P., Shivas, R. G., Jeewon, R., Pongsupasamit, S., Marney, T. S., Taylor, P. W. J., and Hyde, K. D. 2008. Epitypification and phylogeny of Colletotrichum acutatum J. H. Simmonds. Fungal Divers. 28:97-108.

45. Thomas, G. J., Sweetingham, M. W., Yang, H. A., and Speijers, J. 2008 Effect of temperature on growth of Colletotrichum lupini and on anthracnose infection and resistance in lupins. Australas. Plant Pathol. 37:35-39.

46. Ureña-Padilla, A. R., MacKenzie, S. J., Bowen, B. W., and Legard, D. E. 2002. Etiology and population genetics of Colletotrichum spp. causing crown and fruit rot of strawberry. Phytopathology 92:1245-1252.

47. Vega-Sánchez, M. E., Erselius, L. J., Rodriguez, A. M., Bastidas, O., Hohl, H. R., Ojiambo, P. S., Mukalazi, J., Vermeulen, T., Fry, W. E., and Forbes, G. A. 2000. Host adaptation to potato and tomato within the US-1 clonal lineage of Phytophthora infestans in Uganda and Kenya. Plant Pathol. 49:531-539.

48. Wharton, P. S., and Dieguez-Uribeondo, J. 2004. The biology of Colletotrichum acutatum. An. Jardin Bot. Madrid 61:3-22.

49. White, T. J., Bruns, T. D., Lee, S., and Taylor, J. W. 1990. Amplification and direct sequencing of fungal ribosomal genes for filogenetics. Pages 315-322 in: PCR Protocols: A Guide to Methods and Applications. M. A. Innis, D. H. Gelfand, and J. J. Sninsky, eds. Academic Press, San Diego, CA.

50. Whitelaw-Wecket, M. A., Curtin, S. J., Huang, R., Steel, C. C., Blanchard, C. L., and Roffey, P. E. 2007. Phylogenetic relationships and pathogenicity of Colletotrichum acutatum isolates from grape in subtropical Australia Plant Pathol. 56:448-463.

51. Yang, H. A., and Sweetingham, M. W. 1998. The taxonomy of Colletotrichum isolates associated with lupin anthracnose. Aust. J. Agric. Res. 49:1213-1223. 